\title{
BMJ Open Exploring senior doctors' beliefs and attitudes regarding mental illness within the medical profession: a qualitative study
}

\author{
Eleonora F Bianchi, Mimi R Bhattacharyya, Richard Meakin
}

To cite: Bianchi EF, Bhattacharyya MR, Meakin R. Exploring senior doctors' beliefs and attitudes regarding mental illness within the medical profession: a qualitative study. BMJ Open 2016;6: e012598. doi:10.1136/ bmjopen-2016-012598

- Prepublication history and additional material is available. To view please visit the journal (http://dx.doi.org/ 10.1136/bmjopen-2016012598).

Received 11 May 2016 Revised 17 August 2016 Accepted 1 September 2016

CrossMark

Department of Primary Care and Population Health, UCL Medical School, London, UK

Correspondence to Dr Richard Meakin; r.meakin@ucl.ac.uk

\section{ABSTRACT}

Objective: To explore the views of senior doctors on mental illness within the medical profession.

Background: There has been increasing interest on the issue of doctors' mental health. However, there have been few qualitative studies on senior doctors' general attitude towards mental illness within the medical profession.

Setting: Large North London teaching hospital. Participants: 13 hospital consultants and senior academic general practitioners.

Methods: A qualitative study involving semistructured interviews and reflective work. The outcome measures were the themes derived from the thematic framework approach to analysis.

Results: Four main themes were identified. (1) 'Doctors' attitudes to mental illness' - doctors felt that there remained a significant stigma attached to suffering from a mental illness within the profession. (2) 'Barriers to seeking help'-doctors felt that there were numerous barriers to seeking help such as negative career implications, being perceived as weak, denial and fear of prejudice. (3) 'Support' - doctors felt that the use of support depended on certainty concerning confidentiality, which for occupational health was not thought to be guaranteed. Confiding in colleagues was rare except among close friends. Supervision for all doctors was raised. (4) 'General Medical Council (GMC) involvement'- doctors felt that uneasy referring colleagues to the GMC and the appraisal and revalidation process was thought not to be thorough enough in picking up doctors with a mental illness.

Conclusions: Owing to the small size of this study, the conclusions are limited; however, if the findings are confirmed by larger studies, they suggest that greater efforts are needed to destigmatise mental illness in the profession and improve support for doctors. Additional research should be carried out into doctors' views on occupational health services in managing doctors with mental illness, the provision of supervision for all doctors and the effectiveness of the current appraisal and revalidation process at identifying doctors with a mental illness.

\section{Strengths and limitations of this study}

- This study provided an in-depth exploration of the views of senior doctors regarding mental illness and their role as doctors.

- Although there was a small sample size of 13 senior doctors, every effort was made through purposive sampling to include a variety of specialties from medicine, surgery and primary care (11 in total). Sampling bias may have occurred due to participants taking part for personal reasons.

- Participants were sampled from one large teaching hospital in North London; thus, further research into other settings would be needed to determine whether the views expressed are generalisable.

- The bulk of the data came from face-to-face interviews, but the main researcher (EFB) also kept a reflective diary and carried out a member-checking process to increase rigor and validity of results. Triangulation using another method of data collection could have further strengthened these results.

- A subset of the data was independently analysed by the second author (MRB) and themes were agreed upon together.

- As a medical student, the main interviewer had a common ground with the participants. This could have facilitated discussion and made her less intimidating to speak with because of her junior role. However, it is important to note the possibility that the researcher's background as a medical student and part of the doctor's working environment could have resulted in reticence among participants in expressing their views to a student.

- A number of potential participants unfortunately declined to take part in the study. Their reasons were not explored, but a few who did participate spoke of issues of confidentiality and anonymity. These issues may have hindered some participants in voicing some of their opinions. 


\section{INTRODUCTION}

Quis custodiet ipsos custodes

Who will watch the watchmen?

It has been over 15 years since Dr Daksha Emson, a 34-year-old psychiatrist who suffered from bipolar disorder, stabbed herself and her 3-month-old baby Freya, covered in accelerant and set it alight. This was a tragic loss and an event that sparked debate and apprehension over doctors' health, how they cope with mental illness and their use of services. ${ }^{1}{ }^{2}$ The 2008 paper 'Mental health and ill health in doctors' ${ }^{3}$ discussed the broad range of issues surrounding mental illness within the profession, such as the low help-seeking behaviour, the stigma, the shame and the secrecy, as well as the need for more accessible and appropriate support services. The paper published in 2010 entitled 'Invisible patients ${ }^{4}$ looked at the negative impact of the profession on doctors' health, the effect of this poor health and the barriers to doctors seeking support. These documents highlight the ever-present stigma surrounding mental illness and call attention to the need to raise awareness of the importance of mental health and wellbeing in doctors. New initiatives have been set up as a consequence, such as the NHS Practitioner Health Programme which is a London-based service designed to deliver mental healthcare specifically to healthcare professionals. $^{5}$

This increase in concern over doctors' health has led to further research focusing on the issues involved. Quantitative studies that have been identified ${ }^{6-13}$ have reported high levels of psychiatric morbidity in doctors and explored their opinions on disclosure, prevalence and risk/protective factors. Qualitative studies on doctors' own attitudes towards mental illness within the medical profession have been rather limited, with those available either focusing only on doctors who suffered mental illness in the past ${ }^{14}$ or only including general practitioners (GPs). ${ }^{15}$ We believe that this is an important topic that deserves further research, particularly in exploring the views of doctors in primary care and those in the surgical and medical specialties, including those who do not have a history of mental illness.

In this study, we have singled out senior doctors because in order to achieve seniority, these doctors have spent a large part of their life in the profession. In fact, over the past 20-40 years, many would have experienced any changes in the culture and attitude towards mental illness within the profession, as well as the changing working environment that could affect mental illness. In addition to this, it is important to note that senior doctors will have different support structures (often being those with the responsibility to provide support to juniors) and, although recent literature ${ }^{12}$ has shown them to be more likely to seek help for a mental illness compared to younger trainees, they may have differing beliefs and attitudes in regards to it, as well as more experience with the General Medical Council (GMC) investigations.

To obtain more information about doctors' perceptions of the management of mental illness within the medical profession, this study also focuses on doctors' opinions towards the GMC. As the organisation that regulates and licenses doctors in the UK, the GMC has a compulsory annual appraisal and 5-yearly revalidation of all doctors. ${ }^{16}{ }^{17}$ As part of this, doctors are required to self-report any mental or physical illness that may affect their fitness to practice and how they are addressing the issue. If a significant concern arises as part of this process or their behaviour and/or practice is thought to pose a risk to the public, an investigation will be opened whereby the doctor will be asked to undergo a GMC health assessment. Doctors can also refer themselves and can be referred by their peers. The assessment involves a physical and mental examination undertaken by two experts appointed by the GMC who report on the person's suitability to be working and may make recommendations for the management of their case. The information gathered is then considered by two GMC case examiners, one medical and one lay. A small percentage of these cases are referred by the case examiners to the Medical Practitioners Tribunal Service and a hearing is conducted by a tribunal consisting of three trained persons. ${ }^{18}$ In the existing literature, there is some evidence to the punitive nature of GMC investigations and the lengthy processes involved. ${ }^{14}$ 19-21 This affected in particular those doctors with a mental illness, with the GMC carrying out an internal review in 2014 on those doctors taking their own lives while under GMC investigation. ${ }^{22}$ There is qualitative literature available that focuses on the views of sick doctors who have been through the GMC process ${ }^{21}$ but this does not cover the general views of doctors. In view of this, a further area that this study examines is that of doctors' general attitudes towards the GMC safety-netting practices and investigations, as well as the issues surrounding this, specifically in regards to doctors being assessed as a result of a mental illness.

\section{METHODS}

The study design was a qualitative interview study examining senior doctors' beliefs and attitudes regarding mental illness in the medical profession, including helpseeking behaviours and beliefs and the use of support services available to them. The principal researcher (EFB) was at the time a third year medical student who carried out this research as part of an intercalated bachelor of science.

\section{Context and sampling}

The study was carried out at a large teaching hospital in North London. The study took place over a 3-month period. EFB recruited 14 senior doctors (13 of which 
were included in the study results) composed of hospital consultants and senior academic general practitioners (SAGP). Unfortunately, one interview was not included in the results due to data retrieval issues.

The doctors were sampled by sending a participant information sheet and consent form either via the hospital's internal post or electronic mail. Participants were purposively sampled from the online consultant directory to include as many different specialties, surgical, medical and primary care.

\section{Data collection}

Data were collected using in-depth semi-structured interviews. EFB also reflected on what was observed during the interviews through a reflective diary, which also recorded any iterative changes to method of data collection or analysis.

\section{Semi-structured interviews}

Face-to-face in-depth semi-structured interviews were carried out with 14 senior doctors by EFB. Demographic information was collected at the start of each interview. The interviews were conducted using a topic guide (see online supplementary appendix 1 ). The topic guide was developed following review of the identified literature. Topics included initial open-ended questions concerning their beliefs about mental illness, their personal experience, attitudes towards mental illness, available services for sick doctors and how the GMC is involved. EFB conducted a pilot interview with a consultant with whom the researcher had personal correspondence with, but who was not based at the teaching hospital and therefore could not be used as part of the study. The topic guide was modified to include new ideas identified throughout data collection. The interviews lasted between 22 and 55 min.

\section{Analysis}

The interviews were transcribed verbatim. Analysis of transcripts was undertaken in parallel with the interviews, enabling modification of the topic guide as other themes emerged. The transcribed interviews and reflective diary formed the raw data used in the analysis. The NVivo V.10 software was used to analyse the interview transcripts using an inductive 'thematic framework approach'. ${ }^{23}$ This process occurred in the following stages:

1. Familiarisation with the data: This involved repeated rereading of the transcripts and reflective diary, allowing EFB to familiarise herself with the data and list key concepts.

2. Identifying a thematic framework: Following familiarisation, recurring themes were identified in the data and highlighted by EFB and an index of data was created to label the transcripts, dividing them into groups that corresponded to identified themes. This formed the basis of the thematic framework.
3. Indexing the transcripts according to the ideas presented: The NVivo V.10 software was used to index and highlight themes within the data.

4. Charting the data: The NVivo V.10 software was used in this stage to rearrange the data into the area of the thematic framework to which they were allocated.

5. Mapping and interpreting the data: The charts of data that were collected were then interpreted to obtain conclusions.

Data analysis started after the first interview so that an iterative approach to data collection could be used in which themes identified in earlier interviews could be explored in subsequent interviews. EFB analysed all of the transcripts independently, and MRB then independently analysed three transcripts and read the reflective diary. The themes identified by EFB and MRB were compared and found to be very similar. After minimal discussion, a final list of themes and subthemes was agreed.

\section{Member checking}

Participants were sent a transcript of their interview and asked for any comments. One participant slightly altered his expression of one concept, but there were no other changes to the text.

\section{RESULTS}

Three hundred and twenty-two senior doctors were contacted. Replies were received from 36 doctors, of which 23 agreed to participate. They were contacted by the principal researcher to arrange an interview time; however, only 14 doctors participated due to doctors no longer maintaining contact with the researcher, interviews being cancelled by participants due to illness or it being impossible to arrange an interview within the time frame of the study.

The participant characteristics are described in table 1.

One participant disclosed a history of post-traumatic stress disorder.

Four main themes, each with a number of subthemes, were identified. These are shown in table 2.

Within the following quotations, omitted words have been shown by entering '...'. Text within brackets has been added by the author.

\section{Doctors' attitudes to mental illness}

Different attitudes were discussed surrounding mental illness within the profession and how it was perceived by senior doctors.

\section{Stigma: mental versus physical health}

Mental illness was perceived very differently by doctors from a physical illness. It was seen to be more longlasting and associated with more suspicion over recurrence. In addition, it was seen to be more easily hidden due to a lack of objectivity with clear scientific tests to prove the diagnosis. 
Table 1 Participant characteristics

\begin{tabular}{|c|c|c|c|}
\hline $\begin{array}{l}\text { Participant } \\
\text { number }\end{array}$ & $\begin{array}{l}\text { Age } \\
\text { bracket* }\end{array}$ & Sex & Specialty \\
\hline 1 & $36-40$ & $M$ & Endocrinology \\
\hline 2 & $36-40$ & $M$ & Radiology \\
\hline 3 & $56-60$ & $M$ & Dermatology \\
\hline 4 & $61-65$ & $M$ & Academic GP \\
\hline 5 & $41-45$ & $M$ & Nephrology \\
\hline 6 & $51-55$ & $M$ & Academic GP \\
\hline 7 & $36-40$ & $M$ & Neurology \\
\hline $8 \dagger$ & $61-65$ & $M$ & Paediatrics \\
\hline 9 & $51-55$ & $M$ & Academic GP \\
\hline 10 & $41-45$ & $M$ & Hepatology \\
\hline 11 & $41-45$ & $M$ & $\begin{array}{l}\text { Orthopaedic } \\
\text { Surgeon }\end{array}$ \\
\hline 12 & $56-60$ & $M$ & Urology Surgeon \\
\hline 13 & $56-60$ & $\mathrm{~F}$ & $\begin{array}{l}\text { Infectious } \\
\text { Diseases }\end{array}$ \\
\hline 14 & $61-65$ & $\mathrm{~F}$ & Paediatrics \\
\hline \multicolumn{4}{|c|}{$\begin{array}{l}{ }^{*} \text { Age bracket was used to maintain greater certainty of } \\
\text { confidentiality due to small number of consultants in certain } \\
\text { specialties. } \\
\text { †This participant's data were lost. } \\
\text { GP, general practitioner. }\end{array}$} \\
\hline
\end{tabular}

Table 2 Themes

\begin{tabular}{|c|c|}
\hline & Subtheme \\
\hline $\begin{array}{l}\text { Theme 1: Doctors' } \\
\text { attitudes to mental } \\
\text { illness }\end{array}$ & $\begin{array}{l}\text { Stigma: mental vs physical } \\
\text { illness } \\
\text { - Unique position of medicine } \\
\text { - Changing attitudes }\end{array}$ \\
\hline $\begin{array}{l}\text { Theme 2: Barriers to } \\
\text { seeking help }\end{array}$ & $\begin{array}{l}\text { Negative job implications } \\
\text { Vulnerability } \\
\text { Fear of prejudice } \\
\text { Lack of illness recognition } \\
\text { and acceptance }\end{array}$ \\
\hline Theme 3: Support & $\begin{array}{l}\text { Organisational and team } \\
\text { support } \\
\text { Relationship with colleagues } \\
\text { Awareness and attitude } \\
\text { towards internal support } \\
\text { services } \\
\text { Awareness and attitude } \\
\text { towards external support } \\
\text { services }\end{array}$ \\
\hline $\begin{array}{l}\text { Theme 4: GMC } \\
\text { involvement }\end{array}$ & $\begin{array}{l}\text { GMC role and GMC health } \\
\text { assessment } \\
\text { Attitudes towards colleagues } \\
\text { referred to the GMC health } \\
\text { assessment } \\
\text { Appraisal and revalidation }\end{array}$ \\
\hline
\end{tabular}

If you have a physical illness there may be a solution for it... an operation and then you're absolutely fine. But with a mental illness it is sometimes perceived as a continuous, chronic issue that may recur. [\#5]
A physical illness, people can see it or you have manifestations of it... your liver function tests are abnormal or you've got a streaming cold or cough or whatever... it's very difficult with mental health, you don't look unwell with it necessarily. [\#11]

When thinking about mental illness in the medical profession, this mind-body dualism was further discussed in that mental illness can affect thought-processes such as reasoning and decision-making, which are vital for the competent execution of clinical medicine. This could be interpreted as doctors with a mental illness posing a greater risk of danger to patients through mistakes in decision-making.

It can affect your ability to reason. If you break your leg you can still make decisions. But if you have been suffering from severe depression then decisions might be impaired. [\#7]

\section{Unique position of medicine}

Although it was generally considered that doctors, as part of the general population, should suffer at least the same extent of mental health problems, reasons for an increased incidence could be due to the cohort of people that are drawn to the profession and the effect that the profession has on the people who partake in it.

Maybe health professionals generally attract people who are of a certain personality or maybe of a personality type which happens also to have risk factors and also it maybe, makes you think that the other is the nature of the work, the training and the work content of patients or the system that we work in. [\#9]

I guess you know, seeing people, extremes, seeing people die, seeing people who are aggressive, difficult, rude, with all the stresses of trying to achieve a job, trying to look after everyone... [\#5]

Another reason why some thought it would be easier for doctors to develop a mental illness was the greater access to substances leading to certain mental illnesses such as addiction among the medical body.

It is easier to get hold of drugs if you're a doctor than if you're not, I don't mean cocaine or heroin, but the other stuff that you can become addicted to. [\#4]

It is incredible how somebody, anaesthetists, share morphine with the patient, get some in the vein of the patient and the rest gives to himself... [\#12]

It is worth mentioning that although many thought that doctors were at an increased risk of developing a mental illness, some put it within the context of being comparable to other high-pressure occupations.

I'm not sure, I mean if you're a top-end banker and you have the same problems, I don't think the situation 
would be any different, or if you're a lawyer, I don't think it's anything specific to the medical profession. [\#2]

\section{Changing attitudes}

The advantage of interviewing senior doctors was that the views obtained were from those who had most likely been in the medical field for a substantial amount of time and had experienced the progression of medicine through this time, and therefore, how attitudes to mental illness had evolved. The general thought was that the situation in regards to stigma and mental illness for doctors and the general population had slightly improved but still very much exists.

In a way I think we have become slightly more open about it but in a way, probably not. So I think we are slightly more open and flexible with people... I think nowadays with changes in people's attitudes, changes in employment, law as well, it's more working around people and their illnesses... but I still think there is still a significant stigma attached to it. [\#5]

Many doctors talked in terms of differences in generations due to changes in training and a greater appreciation of one's well-being within younger cohorts, with changes in the system (such as working hours and days off) protecting people from burnout and stress.

I suspect younger people are more sort of touchy-feely. In general this is a whole generational gap I think... there's a more open attitude towards it [mental illness] I think in the young generation, both in general society and in medical training. [\#2]

My generation worked really hard as house officers, where you were on call and I had one day off a month... the people that are coming through later are, I'm sure, prepared to work just as hard but have never worked hard in the way that we did, so that's a sort of clash of cultures a bit... I think generations that come will probably be better, will suffer less problems to some extent because they're more used to looking out for themselves. [\#10]

\section{Barriers to seeking help}

Many participants interviewed believed that most doctors are not open about their mental well-being and that many do not seek help when suffering from a mental illness.

\section{Negative job implications}

A great barrier for doctors was that of negative career implications. Many of the senior doctors interviewed discussed the fear of seeking help in case they were reported, resulting in the possibility of being struck off from the medical register. For one participant, this was tied to a loss of financial income and the consequences that this would entail.
I mean professionally you might be looking at being drawn off the line, so you're no longer able to operate, you're not able to work...I think you're also looking at an income that's lost. And you know, if you're no longer able to work for years that's quite a substantial income that you're losing. How can I put it? An incentive to carry on working and to not acknowledge that these things are going on. [\#2]

It was also revealed that how admitting to a mental illness, even when the senior doctor was able to continue working, could often have serious career progression implications. The following was a personal experience from a participant who described this occurrence:

A colleague of mine ran out of sertraline the other day and she openly said 'I can't get to my GP for two weeks'...she was overheard saying that and when she was being considered for another post in the hospital, it was brought up that she was on sertraline and therefore wasn't suitable, and that's outrageous... she's done the right thing and she's open about it, and this was held against her. [\#13]

\section{Vulnerability}

Doctors were thought to want to project a certain professional image, to patients and to colleagues; therefore, admitting to a mental illness was seen as a weakness and a way that undermined them as a professional.

Part of being a doctor I think is performance, as for any job really, part of the performance is to appear as someone with confidence, wisdom, erm you know, certainty, among other things. And it would make it difficult to do that job if you were admitting vulnerability. [\#9]

It was believed that doctors, as people who have to treat others, do not find their role as physicians compatible with a sick role similar to that of their patients.

Often as a doctor you have to be the person that everyone perceives as being strong, who is looking after all the other patients where you know, you are not necessarily meant to be ill yourself as well. [\#5]

\section{Fear of prejudice}

There was also a notion that doctors were to blame themselves for their poor mental health and therefore could be judged by others for not preventing any problems.

The first thing to say is well it's got to be about, you know, organising your life a bit better and then you'll feel fine, because I think mental health can be perceived as being something where if people were a little bit more organised they would sort it out. [\#11]

We come from a tradition that says that our behaviour and our thinking are under our control and so if we go wrong we are failures. [\#4] 
Maintaining productivity was also an issue for doctors, whereby suffering from a mental illness could be perceived as lagging behind and letting colleagues down on work that needs to be completed. This was not only seen as failing the expectations of the profession in carrying out a service but also fear over being distrusted in one's clinical decisions due to the possibility of later recurrence.

Something about medicine of you know, 'just get on with it, don't moan', you know, 'it's tough for everyone, you just have to cope with it'... it is that selfish, pragmatic perception of 'what does this mean for me? If they're not working that's going to make my life a lot more difficult' and I think that's always a real tension within that relationship. [\#6]

[People] would always be questioning you after that as to whether you've really made a full recovery and always looking at you, you know, if you make, if you have a difficult decision to make you'd feel like you're being questioned perhaps whether you were making it correctly and you might feel people questioning whether your depression had recurred. [\#7]

\section{Lack of illness recognition and acceptance}

Another barrier to seeking help was seen to be a lack of self-recognition and acceptance due to a great element of denial.

I know colleagues who do all sorts of maladaptive things: they hit the bottle, they probably get very stressed out, they get all sorts of diversionary techniques so that they don't address the issues that may be going wrong with them. [\#6]

No question, there are cases which I've been through, there was denial and the doctors and their consultants did not come to terms with them until they absolutely completely broke down and had an acute emergency admission to the mental health unit. [\#12]

\section{Support}

During the interviews, awareness and attitudes towards support structures were discussed.

\section{Organisational and team support}

Participants identified the importance of a good organisational infrastructure that is able to maintain a good working environment, allowing doctors to have space to work with issues when they arise.

The intragroup mechanisms for flexibility, I think can sometimes help people's mental health because it can provide an internal flexibility that responds to the fact that we all have different experiences, some people have ups and downs, and so can be responsive to needs. [\#1]

If you're in a service which is under-resourced, stretched, poorly managed and all those things can add to your burden and increase your level of burnout. [\#9]
Nevertheless, this infrastructure could sometimes lead to collusion that was a common topic discussed, whereby the system or peer network would allow a doctor to continue working and allow his illness to remain hidden.

I worked for a registrar who operated better when he was drunk than when he wasn't. If you wanted to find him out of hours when he was on duty and you were the on-call SHO for the labour unit, you had a pub to ring, the system was that well organised. [\#4]

I had a colleague once who took prolonged absences, which officially were down to stress, but I suspect given that I've known him for 15 years and this happened when we were training together in medical school as well, I suspect that it was more manic depression... it was definitely very carefully spun to us... So I do think that had he had Crohn's or something, people would have been much more forthcoming say 'yeah, he's got Crohn's, he's just not coming in'. There's definitely quite a bit of a stigma and some people don't necessarily treat it openly or discuss it openly. [\#2]

\section{Relationship with colleagues}

Doctors generally said that they would not inform colleagues if they had a mental illness. This was mainly driven by the desire to keep things within one's control.

No you can't, talking to colleagues is really just defaming and defusing the issue and is irresponsible... it has to be reported in a formal documented channel then nobody can diffuse it behind you on your behalf. [\#12]

Many senior doctors stated that unless they were close friends, doctors had little awareness of their colleagues' mental well-being.

I know someone... he was on some course and he had a breakdown... I heard he completely collapsed, and no one had noticed and it's not anything against them, it's again difficult when you're tied up thinking about other issues and patient care. [\#14]

When I started telling some friends, well no, some colleagues about it, there was a clear lack of support. No discussion, no discussion, it was almost like 'oh well erm, when you've had a holiday you'll feel much better'. They didn't want to go there. Just didn't want to go there. [\#13]

I know quite a few of my colleagues who are on sertraline but they are my friends as well and that's why I know, but they wouldn't tell their colleagues. [\#13]

\section{Awareness and attitudes towards internal support structures}

Existence of occupational health was well known to senior doctors interviewed. However, there were deep-rooted anxieties about it being part of the employer's organisation, with issues of privacy and confidentiality. 
I may be quite worried about that in a way and I think of occupational health as the organisation that will determine when I am fit to return to work if I've been ill for some reason or another. [\#3]

I wouldn't want to use the hospital's own services because I don't really want, with Cerner and stuff, I don't want my medical records in the hospital... so some of my colleagues can look up my notes and see that I am under the care of a psychiatrist, the sort of thing that would create a lot of gossip. So yeah, that would definitely factor in my thinking... I don't really want my colleagues going 'oh clinic appointment yesterday, I wonder what happened there', which they could do! And so I would rather keep it outside the hospital. [\#2]

In regards to internal support systems, it was mentioned that doctors in all specialties should have independent confidential supervisors for them to talk about their non-clinical needs and concerns. One participant with personal experience of private supervision went into detail about this:

We don't have a concept whereby we can be supervised, not clinically but almost emotionally and psychologically... rather like psychologists do... I just go and see somebody for supervision, talk about anything, talk about management, having difficulty with one team member and what's the best way to go about it, it's hugely helpful but I've had to do it on my own... You need an unconditional relationship where a friendship is not at risk if you say something that's not going to be acceptable. [\#13]

\section{Awareness and attitudes towards external support structures}

When doctors thought about what they would do if they were ever in a position where they thought that they were no longer fit for work due to a mental illness, most stated that their first port-of-call would be their GP.

I would want a third party opinion, so I would go to my GP, go through the normal routes that a non-doctor would go through. [\#2]

However, when doctors felt that they did not have a good long-standing relationship with their GP, often they would not seek support from them.

I haven't actually probably visited my GP so I don't feel that I have a connection with my GP, so probably first thing to go and talk to the GP, probably myself I don't feel it. Though it is wrong. Should be the first stop. But me, I have to be honest, no I would not go to my GP. [\#12]

Although doctors were generally aware that external support services existed and were available, senior doctors' specific knowledge and interpretation of services varied. A common response was that of having a limited knowledge of services but knowing where to look for them if they were ever in need.
You can probably ring occupational health and you could contact your GP, you could probably contact someone like the BMA, or like medical events folk and they would all have ways of signposting so I kind of know how I could find the help if I so wanted to or needed to, but I don't really know anything about, it's a bit like I know how to get a car serviced, but I don't actually, you know? [\#10]

Frequently, doctors expressed the advantage of external services was that they were independent and had the doctor's best interest at heart. They would not be in contact with the employer organisation and would not allow colleagues to become aware of the doctor's situation.

But in a way it would be an independent body that would be independent of your own unit so other people would not be able to access your data, other people would not be able to see you going in. [\#5]

However, there was the disadvantage of not speaking with someone you knew well or whom you trusted, which was something appreciated by doctors.

I still think that the personal approach might be the better way. You know, using your own existing net of contacts might be the first step and that first step might lead you to another source of help. [\#4]

\section{GMC involvement}

\section{GMC role and health assessment}

All doctors were aware of the role of the GMC and it was generally seen as the 'court of last resort'. When speaking about the possibility of having to refer a colleague to the GMC for a health assessment, most participants mentioned the desire to speak to the colleague first and many thought that there were better ways of dealing with the situation. There were also some concerns as to the impact that referring to the GMC would have on the person's career and life, making most doctors feel uncomfortable to do so.

I'm definitely aware of colleagues who have, you know, escalated to the point where they have had very substantial problems and it has had an impact on their ability to work. It would be a very uncomfortable thing to actually do, dob somebody in effectively. It would have a profound effect on their lives and their livelihood. [\#6]

There were also concerns as to how efficient the GMC would be at dealing with the problem, and how long it would take for the process to come to a decision on how to proceed. One participant discussed her experience of a colleague being referred to a GMC health assessment which, despite not being due to mental illness, conveyed her attitude towards the process and system as a whole:

We told the GMC and the poor woman waited for about a year before she heard from them and I thought that 
was terrible, so I just don't think they have the capacity or the knowledge or the ability... I was really upset for her, because I wanted to help her and so I would be very nervous about referring someone to the GMC. [\#14]

There were also thoughts regarding the concept of branding someone guilty simply through referral.

Every time you make a referral, this person is guilty until proven otherwise and not the other way around... because people are worried about patient care and when you want to do something like that, you might really be putting this colleague on suspension... and myself I wouldn't do it. [\#12]

\section{Attitudes towards colleagues referred to the GMC health assessment}

When discussing attitudes towards colleagues who had been referred to a GMC health assessment, participants expressed their sympathy and support for them, while at the same time realising their concerns and anxieties over the colleague's clinical abilities and fitness to practice for the future.

I suspect I'd be anxious about their ability to return to the work environment, certainly I know within our practice everybody is overstretched and stressed and a normal day is a challenge. So the idea that you would put somebody back into that working environment who was struggling would be a source of anxiety... I suspect you'd want to meet with them, you'd want to find out how they are... whether any limitations had been placed on their registration. [\#6]

\section{Appraisal and revalidation process}

The comments made by doctors were generally negative in regards to the appraisal of doctors suffering from a mental illness. It was thought that the process was not very robust.

I've had my appraisal, I'm going to have my revalidation tomorrow, and the health-related part is a simple selfassessment 'I am in good health'-yes or no. So I don't think it's very thorough. [\#2]

Another apprehension was on the overall effectiveness of the system at following through concerns about doctors. One participant expressed frustration and dissatisfaction with their experience of the process.

I am really concerned that it's going to end up in a huge administrative bottleneck that every other blooming thing does. For example, I am involved in really a very big mediation meeting about somebody's, a senior doctor's, behaviour. It was an appalling process, and all these tick boxes were put there that were going to be checked again in six months. I didn't even bother to answer, I wasn't followed up, nothing, it's fallen flat on its face. That's the problem with these things, followthrough. [\#13]

\section{DISCUSSION}

There is increasing awareness of the importance of mental illness within the general population, as well as the medical profession. However, little is known specifically about the views of senior doctors in the UK concerning mental illness among members of the profession. In common with other qualitative studies, this study did not intend to sample the views of a representative sample of senior doctors but rather to provide a more detailed insider perspective on this important issue. The study identified four themes: 'Doctors' attitudes to mental illness', 'Barriers to seeking help', 'Support' and 'GMC involvement'.

In the theme 'Doctors' attitudes to mental illness', the finding that there is a great degree of stigma attached to mental illness in the medical profession was found in the existing literature. ${ }^{13} 1424 \quad 25$ In this theme, we described various aspects that were discussed regarding attitudes towards mental illness, including the difference between how mental and physical illness are conceived, how the medical profession compares to the general population in suffering from mental illness and the changing attitudes that senior doctors are experiencing in regards to it. Mental illness was perceived to be more stigmatised than physical illness among doctors. Some participants viewed doctors' mental health as no worse than the general population. This is consistent with the quantitative study by Hassan et al..$^{9}$ However, the high stress attributed specifically to the medical profession has been reported in numerous other studies. ${ }^{711}$ This included the view that doctors have a greater exposure to emotional issues surrounding death and patient suffering. ${ }^{11}$ The finding that mental illness in doctors is due to occupational and individual risks is consistent with the findings of the narrative literature review by Brooks et al. ${ }^{24}$

In the theme 'Barriers to seeking help', fear of career repercussions was seen as a major barrier. This is consistent with previous research. ${ }^{9}{ }^{24}$ Psychological barriers, such as perceiving mental illness as a weakness and the inability of doctors to place themselves within a sick role, is described in the existing literature. ${ }^{14}{ }^{24}$ Colleagues were seen to have a significant negative impact on doctors seeking help due to fear of prejudice for suffering from a mental illness, a phenomenon also identified by Henderson et al. ${ }^{14}$ While some of these barriers are not specific to the medical profession, they have particular resonance because of the specific roles and responsibilities of doctors. The lack of recognition and acceptance of mental illness due to lack of insight and reflection is consistent with other studies' findings. ${ }^{12} 1526$ Other reasons for not seeking help were brought up in Cohen $e$ t $a l \mathrm{~s}^{12}$ quantitative survey, such as only perceiving that they had mild symptoms, not seeing the relevance of seeking help and believing that they would be able to deal with the problem themselves. Adams $e t a l \mathrm{~s}^{13}$ study also discusses fears of letting patients and colleagues down, as well as lack of locum cover as barriers to 
seeking help. Although our study focused on barriers to seeking help, enablers to seeking help have been described in the literature such as sensing a professional responsibility to do so, wanting advice on how to manage work alongside mental ill health, seeking emotional support, as well as obtaining treatment, getting time off or negotiating a change in workload. ${ }^{12}$ These are all additional views that did not emerge in our study but that should be considered when thinking about why doctors do not seek help for their mental illness.

The theme on 'Support' explored the importance to senior doctors of organisation and team assistance. The issue that a lack of infrastructural support in a team, poor organisation and less flexibility in workload could increase rates of mental illness is present in other studies. ${ }^{6} 1127$ Another finding consistent with existing literature was that of doctors not wanting to report to a colleague and the preference of talking to a friend. ${ }^{9}$ The study's finding regarding senior doctors' views on using occupational health services does not appear in the existing literature, but there was evidence in the literature on the importance of confidentiality for doctors, ${ }^{924}$ something that was attributed in the study to a lack of trust in using occupational health services. An idea brought up in this study that was not found elsewhere was that of all doctors having supervisors, enabling them to have someone independent to speak with about problems they may be having in the clinical environment and daily life.

The study's findings on 'GMC involvement' added to Brooks $e t$ als study ${ }^{21}$ by giving the general attitudes of senior doctors, not just the views of doctors who had been through GMC investigations themselves. The views of the GMC process being lengthy and time-consuming were consistent with Brooks et al s study, as well as the concept of branding someone guilty by referring them. Opinions on the role of the appraisal and revalidation process do not appear to have been reported in the existing literature and, in our study, were generally negative in regards to picking up those with a mental illness that is affecting doctors' work.

\section{STRENGTHS AND LIMITATIONS}

A strength of this study is that it is an in-depth exploration of the views of senior doctors regarding mental illness and their role as doctors. Although the study had a small sample size of 13 , every effort was made through purposive sampling to include a variety of specialties (11 different specialties in total). This meant that a wide range of views could be included, including both SAGPs to cover primary as well as secondary care. The sample was recruited from a single site and it is possible that had the sample been recruited from a number of hospitals more themes could have been identified. However, we believe that it is likely that data saturation was achieved as no new themes emerged from the last three interviews.
As a qualitative study we did not attempt to gather a generalisable sample and it is possible that sampling bias may have occurred as those doctors who chose to respond to our invitation and take part in the interviews may have had specific personal reasons to do so. Although a member-checking process was carried out to check the transcripts were an accurate record of the participants' views, respondent validation of the interpretation was not carried out. The results would have been strengthened by triangulation using another method of data collection. EFB analysed all transcripts and MRB analysed three of these to increase reliability in the interpretation, however this could have been further improved by increasing the number of transcripts analysed by MRB and increasing the number of coders.

As a medical student, the main interviewer was a member of the profession and shared an understanding of 'medical life' which may have facilitated discussion. Also, her junior role may have made her less intimidating to talk to. However, it is important to note the possibility that the researcher's background as a medical student and part of the doctor's working environment could have resulted in reticence among participants in expressing their views to a student.

Unfortunately, a number of potential participants declined to take part in the study. Although their reasons were not explored, a number who did participate spoke with the researcher about issues of confidentiality and anonymity. One participant summarised very well what came across from many doctors during the interviews:

What's surprising is just thinking about it and actually it's quite uncomfortable, and that's fine it should be! And you're definitely thinking, how much do you say? How much do you genuinely express your thoughts on tape? [\#6]

This is of value in itself as it shows the deep-rooted concerns and the reluctance in disclosing some thoughts, irrespective of the reassurance and safe environment provided by the researcher and study premises, and may have stopped some participants voicing some of their opinions.

\section{IMPLICATIONS}

This study focused on the views of senior doctors regarding mental illness within the medical profession. The views of this group of doctors are important because of their experience of the practice of medicine and their position as role models for more junior members of the profession. In addition, we wanted to explore the views of all doctors, regardless of whether they had any personal experience of suffering from a mental illness or not. Although many of our findings are consistent with the existing literature, a number of novel areas were identified that have not been reported previously. This may be because of the professional experience and 
senior roles held by this group of doctors. If these findings are supported by further research, they may have implications for the way in which doctors with a mental illness are identified and managed, as well as aiding in the prevention of mental illness within the medical profession.

Although there is published literature regarding how the profession deals with doctors who have a mental illness that may affect their ability to practice, we believe that our study does provide further evidence in highlighting the stigma surrounding mental illness that is still present within the medical profession, as well as emphasising the substantial barriers that doctors face when seeking help.

Our study suggests that medical education and the professional bodies need to address not only the continuing stigma associated with mental illness in general but also specific issues in relation to aspects associated with the practice of medicine, such as beliefs concerning its effect on clinical decision-making processes. These issues need to be addressed in the curriculum for the training of doctors and also by acknowledging the importance that senior doctors have as role models for their junior colleagues.

The findings of this study stress the importance of good organisation and team work in a clinical group in order to relieve pressure, reduce isolation and promote medical practitioners' well-being. It can encourage doctors to be more attentive to their own thoughts and feelings, as well as the actions of their colleagues.

It is in the area of support for doctors with mental health problems that this study has identified additional areas which may have an impact on the way doctors with mental health problems are managed. Senior doctors highlighted mistrust of occupational health services in relation to mental health problems mainly related to privacy and confidentiality. This suggests that these services need to be tailored to the complex needs of doctors becoming patients and have confidentiality as a priority. Together with other studies, ${ }^{5} 28$ our study suggests that responsibility for management of mental health problems within the medical profession should not be placed solely on occupational health departments. Further research needs to be performed to determine whether this distrust of occupational health services in relation to doctors with mental health problems is widespread in the profession and if so what can be done to address these concerns. Another novel strategy to improve the management of mental illness identified by senior doctors in our study was provision of supervision for all doctors to help them deal with the stresses of medical practice. This is something that has been a normal part of psychotherapy practice for a long time and may have a role in prevention of mental illness among doctors as well as the management of doctors with a mental illness. Further research to determine the acceptability, practicality and effectiveness of such a strategy should be undertaken.
Our study is consistent with previous research ${ }^{21}$ suggesting that senior doctors view the GMC process as punitive and unsupportive. This clearly needs to be addressed if doctors seek help when they become unwell. However, our study would suggest that senior doctors believe the role of the appraisal process in identifying mental illness is ineffective. This is a novel finding and, if their impression is confirmed by further research, may have significant implications for the appraisal and revalidation process.

Acknowledgements The authors thank the participants who agreed to share their thoughts and experiences for this study.

Contributors EFB designed the study, carried out the interviews, analysed the data and was the main author. MRB supervised the design and analysis phases. RM and MRB contributed to the writing of this paper.

Funding This research received no specific grant from any funding agency in the public, commercial or not-for-profit sectors.

\section{Competing interests None declared.}

Ethics approval Ethical approval was granted by UCL Research Ethics Committee. Written and verbal informed consent was obtained from participants. The interviews were conducted privately and the participants' transcripts were anonymised. If there was disclosure of information during the interview that suggested that the doctor or their patients were at risk, EFB had a responsibility to disclose this information. This did not occur.

Provenance and peer review Not commissioned; externally peer reviewed.

Data sharing statement No additional data are available.

Open Access This is an Open Access article distributed in accordance with the Creative Commons Attribution Non Commercial (CC BY-NC 4.0) license, which permits others to distribute, remix, adapt, build upon this work noncommercially, and license their derivative works on different terms, provided the original work is properly cited and the use is non-commercial. See: http:// creativecommons.org/licenses/by-nc/4.0/

\section{REFERENCES}

1. North East London Strategic Health Authority. Report of an independent inquiry into the care and treatment of Daksha Emson M.B.B.S., MRCPsych, MSc. and her daughter Freya, 2003. http:// www.simplypsychiatry.co.uk/sitebuildercontent/sitebuilderfiles/ deinquiryreport.pdf (accessed 30 Apr 2016).

2. Department of Health. Good doctors, safer patients. Proposals to strengthen the system to assure and improve the performance of doctors and to protect the safety of patients, 2006. http://webarchive. nationalarchives.gov.uk/20130107105354/http://www.dh.gov.uk/ prod_consum_dh/groups/dh_digitalassets/@dh/@en/documents/ digitalasset/dh_4137278.pdf (accessed 30 Apr 2016).

3. Department of Health. Mental health and ill health in doctors, 2008. http://webarchive.nationalarchives.gov.uk/20130107105354/http:// www.dh.gov.uk/prod_consum_dh/groups/dh_digitalassets/@dh/@en/ documents/digitalasset/dh_083090.pdf (accessed 30 Apr 2016).

4. Department of Health. Invisible patients: report of the working group on the health of health professionals, 2010. http://www. champspublichealth.com/writedir/4344Invisible\%20patients $\% 20-\%$ 20The\%20Working\%20Group\%20on\%20the\%20Health\%20of\% 20Health\%20Professionals\%20-\%20Report.pdf (accessed $30 \mathrm{Apr}$ 2016).

5. Practitioner Health Programme. The first five years of the NHS Practitioner Health Programme. London: Practitioner Health Programme, 2013.

6. Bovier PA, Arigoni F, Schneider M, et al. Relationships between work satisfaction, emotional exhaustion and mental health among Swiss primary care physicians. Eur J Public Health 2009;19:611-17.

7. Caplan RP. Stress, anxiety and depression in hospital consultants, general practitioners and senior health service managers. BMJ 1994;309:1261-3.

8. Guest RS, Baser R, Li Y, et al. Cancer surgeons' distress and well-being, I: the tension between a culture of productivity and the need for self-care. Ann Surg Oncol 2011;18:1229-35. 
9. Hassan TM, Ahmed SO, White AC, et al. A postal survey of doctors' attitudes to becoming mentally ill. Clin Med (Lond) 2009:9:327-32.

10. Miller L. Doctors, their mental health and capacity for work. Occup Med (Lond) 2009:59:53-5.

11. Ramirez AJ, Graham J, Richards MA, et al. Mental health of hospital consultants: the effects of stress and satisfaction at work. Lancet 1996;347:724-8.

12. Cohen D, Winstanley SJ, Greene G, et al. Understanding doctors' attitudes towards self-disclosure of mental ill health. Occup Med (Lond) 2016;66:383-9.

13. Adams EF, Lee AJ, Pritchard CW, et al. What stops us from healing the healers: a survey of help-seeking behaviour, stigmatisation and depression within the medical profession. Int $J$ Soc Psychiatry 2010;56:359-70.

14. Henderson M, Brooks SK, Del Busso L, et al. Shame! Self-stigmatisation as an obstacle to sick doctors returning to work: a qualitative study. BMJ Open 2012;2:e001776.

15. Thompson WT, Cupples ME, Sibbett $\mathrm{CH}$, et al. Challenge of culture, conscience, and contract to general practitioners' care of their own health: qualitative study. BMJ 2001;323:728-31.

16. General Medical Council. Our role, 2014. http://www.gmc-uk.org/ about/role.asp (accessed 30 Apr 2016).

17. General Medical Council. Ready for revalidation. Supporting information for appraisal and revalidation. Manchester: GMC, 2012. http://www.gmc-uk.org/RT__Supporting_information_for_appraisal and_revalidation__DC5485.pdf_55024594.pdf (accessed 30 Apr 2016).

18. General Medical Council. Doctors under investigation-health assessments, 2014. http://www.gmc-uk.org/concerns/doctors under investigation/health_assessments.asp (accessed 30 Apr 2016).
19. Bourne T, Wynants L, Peters M, et al. The impact of complaints procedures on the welfare, health and clinical practise of 7926 doctors in the UK: a cross-sectional survey. BMJ Open 2015;5: e006687.

20. Learner S. Doctors and mental health. BMJ Careers, 2011. http:// careers.bmj.com/careers/advice/view-article.html?id=20002383 (accessed 30 Apr 2016).

21. Brooks SK, Del Busso L, Chalder T, et al. 'You feel you've been bad, not ill': sick doctors' experiences of interactions with the General Medical Council. BMJ Open 2014;4:e005537.

22. General Medical Council. Doctors who commit suicide while under GMC fitness to practise investigation, 2014. http://www.gmc-uk.org/ Internal_review_into_suicide_in_FTP_processes.pdf_59088696.pdf (accessed 30 Apr 2016).

23. Pope $\mathrm{C}$, Ziebland $\mathrm{S}$, Mays $\mathrm{N}$, et al. Analysing qualitative data. $B M J$ 2010;320:114-16.

24. Brooks SK, Gerada C, Chalder T, et al. Review of literature on the mental health of doctors: are specialist services needed? J Ment Health 2011;20:146-56.

25. Schulze B. Stigma and mental health professionals: a review of the evidence on an intricate relationship. Int Rev Psychiatry 2007;19:137-55.

26. Center $\mathrm{C}$, Davis $\mathrm{M}$, Detre $\mathrm{T}$, et al. Confronting depression and suicide in physicians: a consensus statement. JAMA 2003;289:3161-6.

27. Crook HD, Taylor DM, Pallant JF, et al. Workplace factors leading to planned reduction of clinical work among emergency physicians. Emerg Med Australas 2004;16:28-34.

28. Harvey S, Laird B, Henderson M, et al. The mental health of healthcare professionals. London: Department of Health, 2009. 